$12.1 ; 13.2$

\title{
Полевой электронный эмиттер в форме иридиевого острия с углеродным покрытием
}

\author{
() Д.П. Бернацкий, В.Г. Павлов \\ Физико-технический институт им. А.Ф. Иофффе РАН, Санкт-Петербург, Россия \\ ฯ E-mail: vpavlov@ms.ioffe.ru
}

Поступило в Редакцию 10 апреля 2019г.

В окончательной редакции 10 апреля 2019г.

Принято к публикации 12 апреля 2019г.

\begin{abstract}
Изучаются свойства полевого электронного эмиттера, поверхность которого получена разложением молекул бензола на иридиевом острие. В результате на вершине острия образуется кристалл графита. Показана устойчивость к адсорбции молекул остаточных газов, а также возможность локализации эмиссии с помощью адсорбции и интеркаляции атомов щелочного металла.
\end{abstract}

Ключевые слова: полевые эмиттеры, электронная эмиссия, углерод, иридий, бензол.

DOI: 10.21883/PJTF.2019.13.47952.17832

Полевые острийные (точечные) эмиттеры электронов обладают уникальными свойствами для получения и фокусировки пучков с большой плотностью тока [1]. Локализованные в малом телесном угле потоки электронов с большой плотностью тока, получаемые из полевых эмиттеров, создают хорошие перспективы для использования их в электронной микроскопии, рентгеновском микроанализе и других видах электроннолучевых методик и технологий. Применение полевых электронных эмиттеров в электронной микроскопии радикально улучшило характеристики приборов [2].

Наибольшее распространение получили электронные эмиттеры в форме острия из тугоплавкого металла, чаще всего из вольфрама. Такие эмиттеры достаточно просты в изготовлении, их легко очистить от объемных и поверхностных загрязнений высокотемпературным прогревом в вакууме. Металлические острийные эмиттеры позволяют получать узкие электронные пучки с рекордно большой плотностью тока [1] и обладают рядом других достоинств.

Основным недостатком металлических эмиттеров является их нестабильная работа в недостаточно хороших вакуумных условиях. Адсорбция молекул остаточных газов приводит к изменению работы выхода поверхности эмиттера. Электронная эмиссия сопровождается образованием ионов, которые бомбардируют поверхность эмиттера, что приводит к изменению рельефа поверхности и соответственно к изменению локальной напряженности электрического поля. С учетом сильной (экспоненциальной) зависимости плотности тока полевой электронной эмиссии от поля и работы выхода такие изменения вызывают значительные отклонения эмиссионного тока и могут привести к гибели эмиттера.

Большей устойчивостью к перечисленным факторам нестабильности работы обладают эмиттеры из различных углеродных материалов [3,4]. В отличие от металлов изготовление острия из углерода (графит, алмаз) представляется трудной задачей. Поэтому во многих работах изучается полевая электронная эмиссия эмиттеров, состоящих из проводящей подложки (металл, полупроводник) и нанесенных на нее различных углеродных образований. В том числе имеются работы, в которых углеродные покрытия предназначены для защиты поверхности металлического острия [5].

В настоящей работе изучаются возможности изготовления комбинированного металл-углеродного полевого электронного эмиттера с помощью разложения органических молекул на поверхности металлического острия. В качестве материала острия выбран иридий, который практически не образует соединений и твердых растворов с углеродом, а в качестве органического вещества - бензол.

Исследования проводились в вакуумной металлической установке полевого эмиссионного микроскопа с помощью методик полевой электронной микроскопии, измерения характеристик полевой электронной эмиссии и полевой десорбционной микроскопии непрерывного действия [6]. Изменения работы выхода поверхности вычислялись из вольт-амперных характеристик Фаулера-Нордгейма для токов полевой электронной эмиссии. Распределение электронов в пучке определялось исходя из полевых электронных изображений с помощью компьютерной программы ImageJ. Эмитируемые образцом электроны и ионы, а также формируемые ими эмиссионные изображения регистрировались детектором, состоящим из двух микроканальных пластин диаметром $56 \mathrm{~mm}$ и люминесцентного экрана. Давление остаточных газов не превышало $10^{-9}$ Torr, пары бензола напускались в камеру через игольчатый натекатель.

Острия изготавливались из иридиевой проволоки путем электрохимического травления в щелочном растворе. Полученные острия отжигались в вакууме при температуре $T=2500 \mathrm{~K}$, в результате чего на вершине острия формировался монокристалл с радиусом закругления порядка 500-1000 nm. Получение углеродных покрытий осуществлялось посредством выдержки 

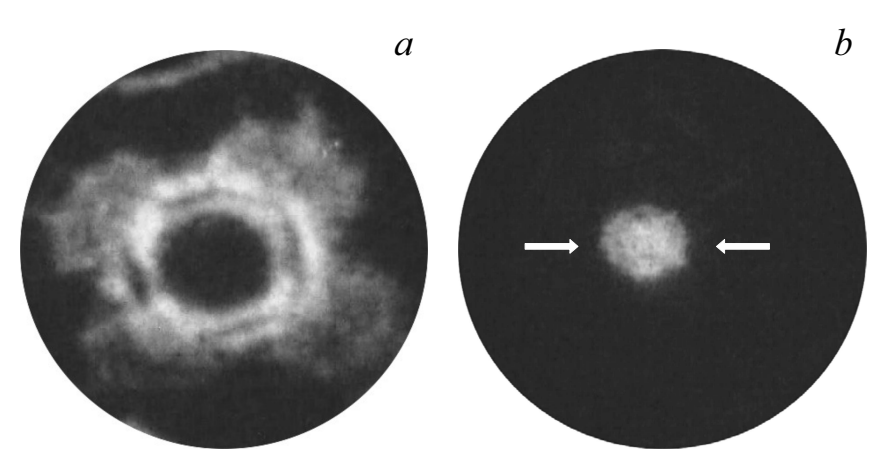

Рис. 1. Полевые электронные изображения: $a-$ иридиевого эмиттера с монокристаллом графита на вершине, $b-$ после напыления цезия и последующего прогрева.

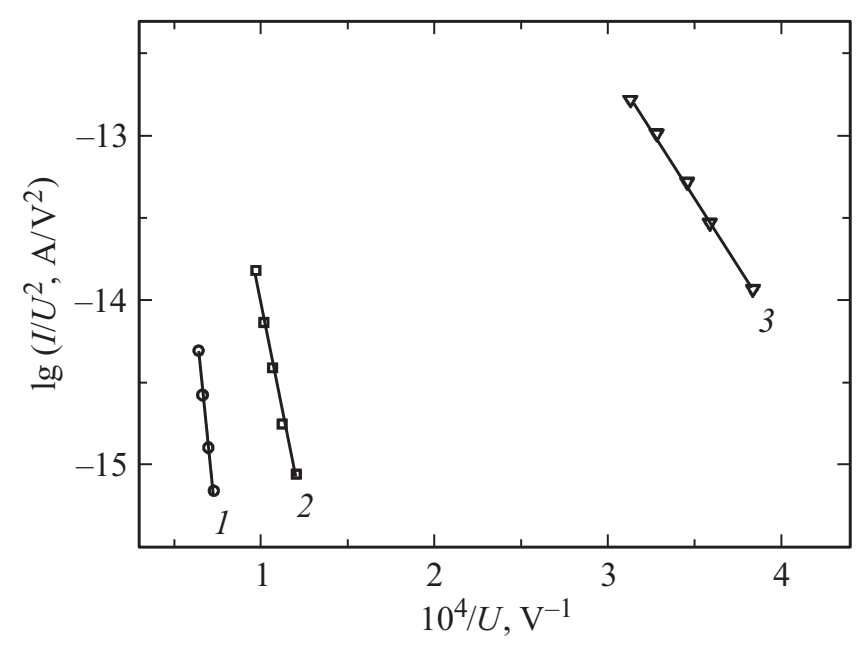

Рис. 2. Вольт-амперные характеристики Фаулера-Нордгейма, соответствующие чистому иридию (1), случаю, показанному на рис. $1, a(2)$ и рис. $1, b(3)$.

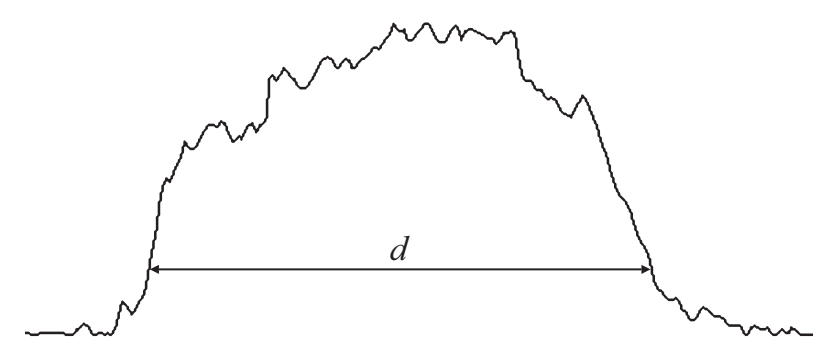

Рис. 3. Распределение электронов в пучке в сечении, обозначенном стрелками на рис. $1, b$.

нагретого острия $(T=1200-1900 \mathrm{~K})$ в парах бензола при давлении $10^{-8}-10^{-5}$ Torr [7].

Структура получаемого углеродного покрытия зависела от экспозиции эмиттера в парах бензола. При малых экспозициях образовывалась пленка графена на плотноупакованных гранях вершины острия и отдельные атомы или их скопления на скругленных участках [8]. При больших экспозициях на вершине острия вырастал монокристалл графита. На рис. 1, $a$ приведено его полевое электронное изображение, а на рис. 2 представлены характеристики Фаулера-Нордгейма чистого иридиевого острия (кривая 1) и выросшего на нем кристалла графита (кривая 2). Эмиссионное изображение и эмиссионные характеристики такого эмиттера (иридиевое острие, покрытое графитом) были устойчивыми к адсорбции остаточных газов. Они не изменялись после выдержки эмиттера в течение нескольких суток в вакуумной камере без откачки (давление возрастало до $10^{-3}$ Torr). В течение месяца на одном и том же покрытом графитом эмиттере проводились эксперименты с напылением щелочных металлов. Прогрев эмиттера для удаления напыленных адсорбатов возвращал его к исходному состоянию (рис. 1, $a$ и кривая 2 на рис. 2).

Напыление щелочных металлов на покрытый графитом иридий приводило к понижению рабочих напряжений на эмиттере, а в определенных случаях - к локализации эмиссии на небольшой площади поверхности эмиттера. На рис. $1, b$ приведен пример полевого электронного изображения, а на рис. 2 (кривая 3) характеристика Фаулера-Нордгейма, соответствующая рис. $1, b$. Эти состояния эмиттера были получены в результате напыления атомов цезия на поверхность графитового покрытия и последующего прогрева при температуре $T=500 \mathrm{~K}$. При таком прогреве часть атомов цезия десорбировалась с поверхности, а часть перешла в интеркалированное состояние внутри графита. Как видно (рис. $1, b$ ), эмиссия электронов идет только с области поверхности над гранью (001) исходного иридиевого острия. Форма пятна эмиссии зависела от исходного состояния графитового покрытия. В одних случаях получалось квадратное пятно, а в других (при других экспозициях в парах бензола) форма пятна была близка к кругу (рис. $1, b)$.

Эмиссия из небольших областей на поверхности эмиттера представляет определенную ценность для электронно-лучевых приложений. В случае полевой электронной эмиссии расходящийся пучок эквивалентен пучку, исходящему из практически точечного источника. Образующийся пучок электронов легко фокусировать. На рис. 3 приведен график относительного распределения электронов по углу вылета в сечении пучка, обозначенном стрелками на рис. $1, b$. Диаметр зоны эмиссии составлял $d \approx 10 \mathrm{~nm}$.

Таким образом, показана возможность получения полевого электронного эмиттера, устойчивого к адсорбции остаточных газов, с помощью выдержки нагретого иридиевого острия в парах бензола. Изучена локализация полевой электронной эмиссии в узком телесном угле с использованием адсорбции щелочных металлов на углеродном покрытии.

\section{Финансирование работы}

Работа выполнена в рамках государственного задания по теме 0040-2014-0021. 


\section{Конфликт интересов}

Авторы заявляют, что у них нет конфликта интересов.

\section{Список литературы}

[1] Фурсей Г.Н. Автоэлектронная эмиссия. СПб.: Лань, 2012. $320 \mathrm{c}$.

[2] Edgcombe C.J., Valdre U. Field emission and electron microscopy // Microscopy and microanalysis. Cambridge University Press, 2000. V. 6. P. 380-387.

[3] Шешин Е.П. Структура поверхности и автоэмиссионные свойства углеродных материалов. М.: Изд-во МФТИ, 2001. $288 \mathrm{c}$.

[4] Forbes R.G. // Solid-State Electron. 2001. V. 45. P. 779-808.

[5] Соминский Г.Г., Тумарева Т.А., Тарадаев Е.П., Рукавищына А.А., Гиваргизов М.Е., Степанова А.Н. // ЖТФ. 2019. T. 89. В. 2. C. $302-305$.

[6] Бернацкий Д.П., Павлов В.Г. // Изв. РАН. Сер. физ. 2009. T. 73. № 5. C. 713-715.

[7] Рутьков Е.В., Галль Н.Р. Физика поверхности твердых тел. Графен и графит на поверхности твердых тел. СПб.: Изд-во Политехн. ун-та, 2013. С. 58.

[8] Бернацкий Д.П., Павлов В.Г. // ФТТ. 2016. Т. 58. В. 1. С. 196-199. 